\title{
Wear of grinding rotors with thermally-sprayed coatings in a high-speed mill
}

TKACHENKO, S.; DVOŘÁK, K.; JECH, D.; SLÁMEČKA, K.; KLAKURKOVÁ, L.; PALOUŠEK, D.; ČELKO, L.

Wear

2018, vol. 412-413, October 2018, pp. $49-59$

ISSN: 0043-1648

DOI: https://doi.org/10.1016/j.wear.2018.05.016

Accepted manuscript

(c) 2018. This manuscript version is made available under the CC-BY-NC-ND 4.0 license (http://creativecommons.org/licenses/by-nc-nd/4.0/), doi:

https://doi.org/10.1016/j.wear.2018.05.016

Final version available from

https://www.sciencedirect.com/science/article/pii/s0043164818303193 


\section{Author's Accepted Manuscript}

Wear of grinding rotors with thermally-sprayed coatings in a high-speed mill

Serhii Tkachenko, Karel Dvořák, David Jech, Karel Slámečka, Lenka Klakurkova, David Paloušek, Ladislav Čelko

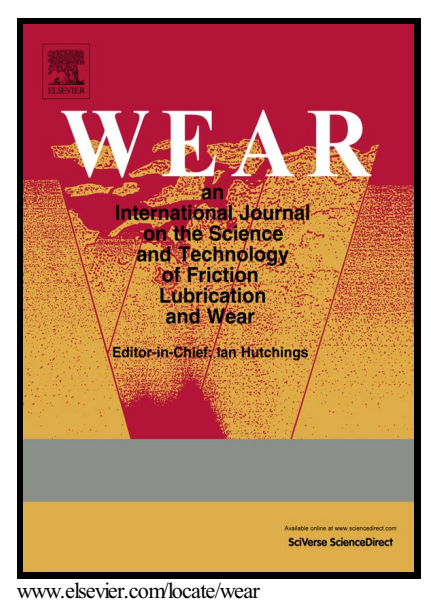

PII: $\quad$ S0043-1648(18)30319-3

DOI: $\quad$ https://doi.org/10.1016/j.wear.2018.05.016

Reference: WEA102427

To appear in: Wear

Received date: 8 March 2018

Revised date: 22 May 2018

Accepted date: 25 May 2018

Cite this article as: Serhii Tkachenko, Karel Dvořák, David Jech, Karel Slámečka, Lenka Klakurkova, David Paloušek and Ladislav Čelko, Wear of grinding rotors with thermally-sprayed coatings in a high-speed mill, Wear, https://doi.org/10.1016/j.wear.2018.05.016

This is a PDF file of an unedited manuscript that has been accepted for publication. As a service to our customers we are providing this early version of the manuscript. The manuscript will undergo copyediting, typesetting, and review of the resulting galley proof before it is published in its final citable form. Please note that during the production process errors may be discovered which could affect the content, and all legal disclaimers that apply to the journal pertain. 


\title{
Wear of grinding rotors with thermally-sprayed coatings in a high-speed mill
}

\author{
Serhii Tkachenko, ${ }^{a, *}$, Karel Dvořák ${ }^{\mathrm{b}}$, David Jech ${ }^{\mathrm{a}}$, Karel Slámečka ${ }^{\mathrm{a}}$, Lenka \\ Klakurkova $^{\mathrm{a}}$, David Paloušek ${ }^{\mathrm{c}}$, Ladislav Celko ${ }^{\mathrm{a}}$ \\ ${ }^{a}$ CEITEC - Central European Institute of Technology, Brno University of Technology, \\ Purkynova 123, 61200 Brno, Czech Republic \\ ${ }^{b}$ AdMaS Center, Faculty of Civil Engineering, Brno University of Technology, Purkynova \\ 139, 612 00 Brno, Czech Republic \\ ${ }^{c}$ NETME Centre, Faculty of Mechanical Engineering, Brno University of Technology, \\ Technicka 2, 61669 Brno, Czech Republic
}

\begin{abstract}
In this paper, the erosion behavior of three types of protective thermallysprayed coatings and non-coated substrate steel was investigated under semiindustrial test conditions using a laboratory high-speed pin mill DESI-11. The grinding in the mill was performed by two counter rotors, on which protective coatings were deposited either by atmospheric plasma spraying (APS) $\left(\mathrm{Cr}_{3} \mathrm{C}_{2}-\mathrm{NiCr}\right.$ and NiCrBSi coatings) or by high velocity oxy-fuel (HVOF) process (WC-CoCr coating). The grinding rotors with deposited coatings were used for milling of the Portland cement, and rotors' weight loss was monitored after milling of $1,3,5,10$, and $15 \mathrm{~kg}$ of this material. The lowest weight loss in the mixed impact erosion conditions was exhibited by WC-CoCr coating, which was followed by $\mathrm{Cr}_{3} \mathrm{C}_{2}-\mathrm{NiCr}$ and $\mathrm{NiCrBSi}$ coatings. The greatest material removal on the anterior and the right lateral faces of rotor pins was
\end{abstract}

\footnotetext{
${ }^{*}$ Corresponding author: Serhii Tkachenko

Email address: serhii.tkachenko@ceitec.vutbr.cz (Serhii Tkachenko)
} 
a result of erosion damage at high impact angles through surface fatigue wear and the following failure of protective coatings down to the substrate. In contrast, the top and the left lateral faces of the pins were subjected mostly to the ploughing and microcutting at oblique impact angles that resulted in significant erosive damage only if hardness of the pin was lower than that of the Portland cement $\left(\mathrm{Cr}_{3} \mathrm{C}_{2}\right.$-NiCr-coated and non-coated steel pins). The study also found a significant disproportion between the volumetric wear losses of various rows of pins of grinding rotors. The central part of the grinding tool consisting of two counter rotors (both rows of 2-row rotor and a middle row of 3-row rotor) suffered more intensive erosion wear than the external part (outer rows of 3-row rotor). The design of the mill and the resulting variability in parameters of milled powder particles at different sites of the grinding tool (such as particle size, particle flux and particle velocity) were considered as main reasons of this phenomena.

Keywords:

high-speed milling, solid particle erosion, thermal spray coatings, surface morphology

\section{Introduction}

2 Milling by collision is one of the most widely spread methods of refining of various powder feedstock (like minerals, ceramics and intermetallics) used for 4 powder technologies. It is typically performed in high-speed milling equipment, so-called "high-speed disintegrators" [1]. Milling occurs as a result of 6 collisions of treated material particles with grinding elements, such as pins 7 or blades of grinding rotors, when a large stresses generated during a large 
number of high-frequency collisions lead to fracture of material. Besides the particle refinement, the treated material is also subjected to mechanochemical activation. This phenomenon can be explained as the change in the reactivity and physico-chemical properties of the final powder product resulting from its bulk and surface structural changes under the influence of mechanical energy supplied by milling [2-5]. Both milling and mechanical activation are considered promising technologies for the enhancement of the reactivity of blended Portland cement constituents (e.g., fly ash) [6-8], and is often used also commercially (Fig. 1). Due to the enhanced reactivity, the resulting cement exhibits improved strength and setting properties. However, a serious problem associated with the use of high-speed disintegrators for fine grinding of construction materials is considerable wear of the working parts of grinding rotors because of erosive action of processed highly-abrasive powders. Wear of working parts leads to a significant reduction in the grinding efficiency of milled materials [9], as well as to the additional expenses for equipment repairs.

An attractive cost-effective solution is the application of protective thermallysprayed wear-resistant coatings, which have already shown their high effectiveness in reducing abrasive/erosive wear in various industrial applications [10-13]. Moreover, the excellent wear resistance of thermally-sprayed hardmetal coatings (based on tungsten or chromium carbide) has been confirmed by some previous laboratory studies in solid particle erosion tests performed under fixed experimental parameters (particle size, particles' velocities, impact angle) [14-18]. However, real milling situations in high-speed mills represent a complex impact erosion phenomena, where material loss of work- 


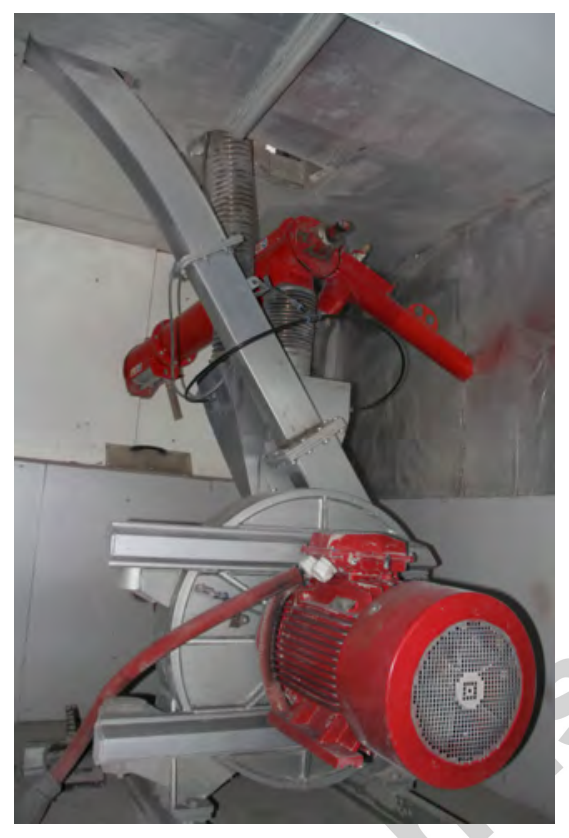

Figure 1: Industrial high-speed disintegrator DESI-18 used for fine grinding of fly ash (courtesy Dastit Technology).

33 ing parts occurs as a result of combined action of microcutting, ploughing,

34 brittle fracture and fatigue wear mechanisms. In this context, semi-industrial 35 wear evaluation of thermally-sprayed coatings is needed in addition to labo36 ratory model tests, however, it is scarcely reported in the available literature $37[14,19]$.

38 In the present study, the evaluation of erosion resistance of several types 39 of protective thermally-sprayed coatings in a laboratory high-speed disinte40 grator was performed, using the Portland cement as an abrasive medium.

${ }_{41}$ The studied protective coatings belonged to three materials groups, i.e. (i) 42 chromium carbide $\left(\mathrm{Cr}_{3} \mathrm{C}_{2}\right)$ nickel-based hardmetal coating, (ii) the coating 43 based on self-fluxing $\mathrm{NiCrSiB}$ alloy, and (iii) tungsten carbide (WC) cobalt- 
based hardmetal coating. These materials are frequently used to improve the resistance to sliding, abrasive and erosive wear in various high-temperature applications (such as gas and steam turbines, aircraft engine parts) [20, 21] as well as in aggressive environments involving medium temperatures, abrasion, erosion and corrosion [11, 22, 23]. Since high impact erosion resistance of these coatings has been mainly proved in model experiments under fixed conditions $[14,18,24-26]$, the evaluation of their real application performance is therefore of the high importance. Used disintegrator DESI-11 (Desintegraator Tootmise OÜ, Republic of Estonia) represents a commercial solution developed for grinding and mechanical activation of different dry powdered materials with the hardness by Mohs up to $6(\sim 700 \mathrm{HV})$ in laboratory and small-industry scales. Portland cement was of interest to the present study because it is well-described and extensively used building binder material among, whose mechanical activation by high-energy milling brings obvious benefits, such as an improvement of the mechanical properties due to mechanical activation of the cement particles and the generation of a favorable particle size distribution [6, 27]. Furthermore, Portland cement is abrasive enough due to its hardness between 5-6 according to the Mohs scale [28] and it also has relatively homogeneous component distribution. Therefore, the employed grinding equipment and chosen abrasive powder allow to estimate the performance of used protective coatings under semi-industrial milling conditions. Another subject of this study was the analysis of the wear mechanisms acting on the working parts of grinding rotors, as well as the intensity and uniformity of wear of these parts, which was mostly behind the research scope of up-to-date research literature on the topic except for few attempts 
69

$[14,19]$.

\section{Experimental}

\subsection{Fabrication of thermally-sprayed coatings}

Initial powders used for the preparation of powder mixtures suitable for thermal spraying were commercially available powders (i) $\mathrm{Cr}_{3} \mathrm{C}_{2}-\mathrm{NiCr}$ (Praxair 1375VM/CRC-300-1, -53+16 m), (ii) NiCrBSi (Hoganas 1660-02, $-53+20 \mu \mathrm{m})$, and (iii) WC-CoCr (GTV 80.76.1, $-45+15 \mu \mathrm{m})$. The nominal composition of the $\mathrm{Cr}_{3} \mathrm{C}_{2}$ - NiCr powder was $20 \mathrm{Cr}, 20 \mathrm{C}$, Ni balance (wt\%). The NiCrBSi alloy powder contained Cr 14.8, Fe 3.7, B 3.1, Si 4.3, C 0.75, Ni balance (wt\%). The nominal composition of the WC-CoCr hardmetal powder was Co 10, C 5.4, Cr 4 and W balance (wt\%).

The $\mathrm{Cr}_{3} \mathrm{C}_{2}$-NiCr and NiCrBSi coatings were prepared from as-received powder feedstock by means of atmospheric plasma spraying (APS) using F4MB-XL gun (Oerlicon Metco, Switzerland). WC-CoCr coating was deposited via the high-velocity oxygen fuel (HVOF) process using the GLC5 gun (GTV, Germany). The spraying parameters are summarised in Table 1. For both processes, the industrial 6-axes robot (IRB2600; ABB, Switzerland) was employed for precise and reproducible deposition. The substrates were grinding rotors for a high-speed mill (shown in Fig. 2a-b and described in detail in the following section) made of the medium carbon steel C45. For each material, a pair of grinding rotors with two rows and three rows of pins were used. Prior to spraying, all rotors were grit-blasted using pure alumina angular particles with the size of about $1 \mathrm{~mm}$. Grit-blasting was conducted at a pressure of $5 \mathrm{~atm}$, using a blasting distance of $100 \mathrm{~mm}$ and an incidence 
angle of $90^{\circ}$. After blasting, the rotors were cleaned in an ultrasonic bath for 10 min and subsequently dried with compressed air. During spraying, rotation of the coated rotors was ensured by a turning machine at a constant speed of $1100 \mathrm{rpm}$. The deposition process was performed until the desired coating thickness of $220 \pm 30 \mu \mathrm{m}$ was reached.

Table 1: Deposition parameters of the coatings studied.

\begin{tabular}{lllll}
\hline Coating designation & Process & Gas supply (slpm) & Current (A) & Spray distance (mm) \\
\hline $\mathrm{Cr}_{3} \mathrm{C}_{2}-\mathrm{NiCr}$ & APS & $\mathrm{Ar}-65 ; \mathrm{H}_{2}-3$ & 600 & 130 \\
$\mathrm{NiCrBSi}$ & APS & $\mathrm{Ar}-57 ; \mathrm{H}_{2}-5$ & 560 & 150 \\
$\mathrm{WC}-\mathrm{CoCr}$ & $\mathrm{HVOF}$ & $\mathrm{O}_{2}-200 ; \mathrm{C}_{2} \mathrm{H}_{4}-60$ & - & 200 \\
\hline
\end{tabular}

\subsection{Wear testing}

Dry erosion testing has been performed in a laboratory high-speed mill (DESI-11; Desintegraator Tootmise OÜ, Republic of Estonia) (Fig. 2a), in which milling of grindable material was accomplished by a pair of counterrotating grinding rotors (designed and manufactured by FF servis company, Czech Republic) (Fig. 2b). Both rotors were made of the medium carbon steel C45 and had the external diameter of $147 \mathrm{~mm}$. This steel grade was chosen due to its moderate hardness $(\sim 270-280 \mathrm{HV})$ with the aim of facilitating the evaluation of wear of milling rotor substrates as compared to the wear of harder protective coatings. According to the scheme shown in Fig. 2c, the left rotor has two rows of pins on a ring-shaped base, while the right rotor has three rows that form concentric circles of various diameters relative to each other. The pins have rectangular shape with dimensions of $2.5 \times 3 \times 3 \mathrm{~mm}$. During milling, the grindable material is delivered to the 
(a)

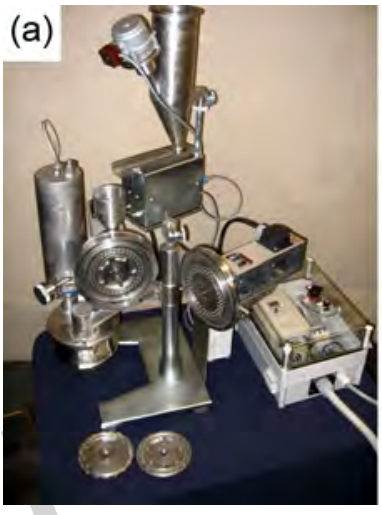

grinding chamber through the middle of the two-row rotor by a continuous feeder, collides with the first row of pins of 2-row rotor and disintegrates while successively passing through posterior rows of pins (Fig. 2c). For comparison with the studied protective coatings, a pair of non-coated 2-row/3-row rotors made of C45 steel was adopted as a reference sample. The rotors' rotation frequency used in the experiment was $12000 \mathrm{rpm}$, which resulted in the maximum impact speed of $92.4 \mathrm{~m} / \mathrm{s}$. The abradant used for erosion testing was the Portland cement with the particle size being in the range of 1-48 $\mu \mathrm{m}$ (Fig. 3). The typical chemical composition of this material can be found elsewhere [29]. Weight loss due to erosion was determined as a ratio between the weight of the eroded rotors after the milling of 1, 3, 5, 10 and $15 \mathrm{~kg}$ of abradant and the initial weight of the rotors. An accuracy of 0.01 mg was achieved for the weight loss measurements.
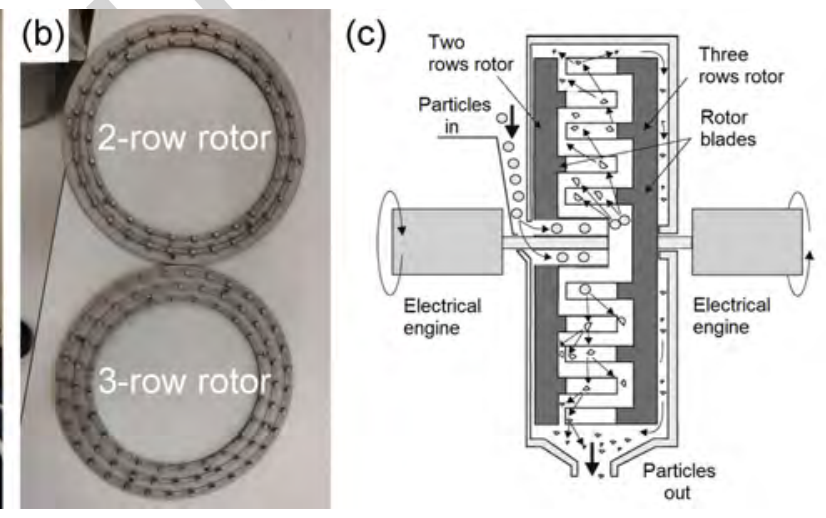

Figure 2: (a) General appearance of the high-speed mill DESI-11, (b) a pair of grinding rotors, and (c) the principal scheme of milling process.

The evaluation of volumetric wear of individual rows of rotor pins was performed using 3D optical scanner (ATOS Triple Scan; GOM, Germany) 


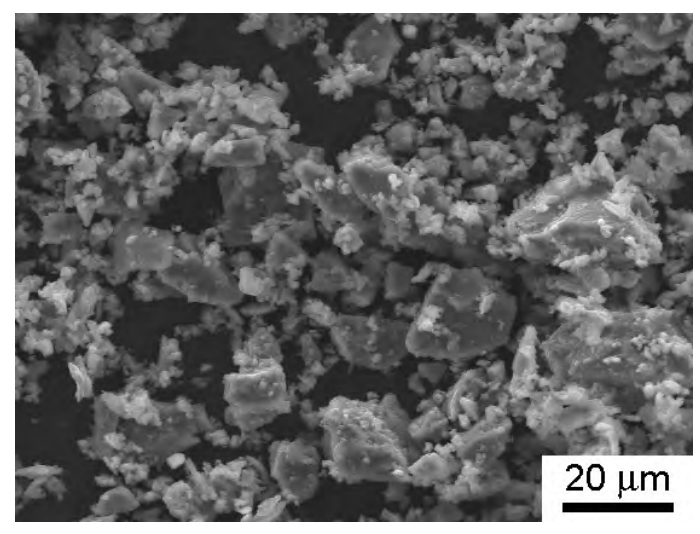

Figure 3: SEM appearance of Portland cement particles used for erosion testing.

equipped with a two-axis rotary table. The evaluation process included (i) 3D digitization of the as-received surfaces of grinding rotors prior to wear testing, (ii) 3D digitization of the abraded surfaces of the grinding rotors after wear testing, and (iii) the comparison of the two measurements using the a specialized software. The measurements were done with MV170 lenses $(170 \times 130 \times 130 \mathrm{~mm})$ calibrated in a small objects arrangement. The measuring point distance was $0.055 \mathrm{~mm}$ (i.e., 18 points $/ \mathrm{mm}$ ), the recommended reference points diameter was $0.8 \mathrm{~mm}$, the measuring distance was $490 \mathrm{~mm}$, the camera angle was $28^{\circ}$, the focal length of camera lenses was $40 \mathrm{~mm}$, and the focal length of projector lens was $60 \mathrm{~mm}$. The final evaluation of digitized profiles of rotor surfaces was performed in the analysis software (ATOS Professional; GOM, Germany), by means of which the relative volume loss of each rotor pin row was calculated as a ratio of its volume change resulted from erosion testing and its initial volume before wear test (Fig. 4). 


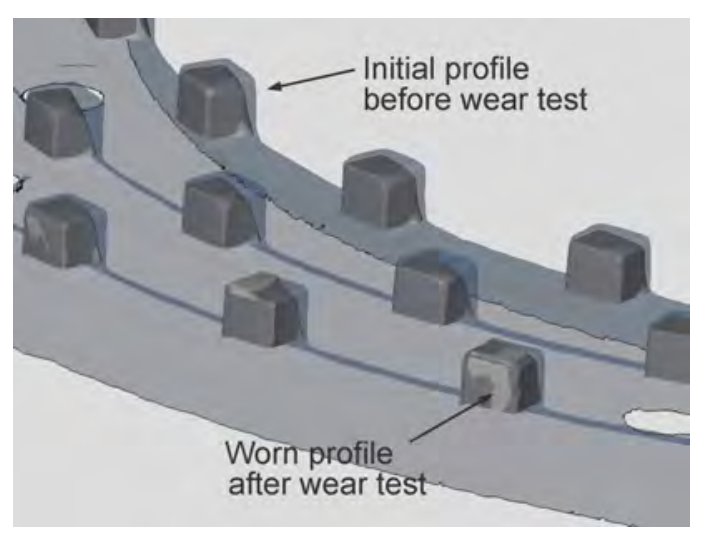

Figure 4: Superposition of initial and worn rotor profiles using 3D optical scanner.

\subsection{Microstructural characterization and evaluation of mechanical properties}

The microstructure of as-received coatings and eroded surfaces of the rotors was analyzed using a scanning electron microscope (SEM) (Lyra3; Tescan, Czech Republic), equipped with an energy-dispersive X-ray spectrometer (EDX) for chemical analyses and elemental mapping. The microstructure preparation included cross-sectioning of the samples, placing the obtained cross-sections into resin molds, grinding with \#90-2000 SiC papers, and final polishing with a $1 \mu \mathrm{m}$ diamond paste. Chemical analysis of as-received coatings was performed using X-ray powder diffractometer (X-ray Smartlab diffractometer; Rigaku, Japan) set up in the Bragg-Brentano geometry with $\mathrm{Cu} \mathrm{K \alpha}$ radiation $(\lambda=0.154 \mathrm{~nm})$ and operated at the current of $30 \mathrm{~mA}$ and voltage of $40 \mathrm{kV}$. The diffraction pattern was collected from $20^{\circ}$ to $100^{\circ}$ with the step size of $0.02^{\circ}$ and the scanning speed of $0.4^{\circ} / \mathrm{min}$. Coating porosity was calculated using the image analysis with the help of a light microscope (DSX-510; Olympus, Japan) and an image analysis software (ImageJ 1.51j8; USA). 
The microhardness measurements were performed on the samples' crosssections using microhardness tester DuraScan-70 (Struers, Austria) under a load of $4.9 \mathrm{~N}$. At least 15 measurements were made for each coating, and average values with their standard deviation are reported in the following text.

\section{Results}

3.1. Microstructural characterization of as-sprayed coatings and their hardness

XRD patterns of as-sprayed coatings are shown in Fig. 5. The major phases identified in the $\mathrm{Cr}_{3} \mathrm{C}_{2}$ - $\mathrm{NiCr}$ coating were $\mathrm{Cr}_{3} \mathrm{C}_{2}$ carbide and two $\mathrm{Ni}$ phases, both with cubic lattices, however, of slightly different lattice parameters. The XRD pattern of the composite NiCrBSi coating showed a considerable number of different phases, which belonged to either hard phases $\left(\mathrm{Cr}_{3} \mathrm{C}_{2}, \mathrm{Ni}_{3} \mathrm{~B}, \mathrm{Ni}_{3} \mathrm{Si}, \mathrm{BN}, \mathrm{W}_{2} \mathrm{C}\right)$ or matrix solid solutions ( $\mathrm{Ni}$ and $\left.\mathrm{Cr}\right)$. In the $\mathrm{WC}-\mathrm{CoCr}$ coating, both $\mathrm{WC}$ and $\mathrm{W}_{2} \mathrm{C}$ hard phases were detected, along with peaks of $\mathrm{W}$.

The microstructural examinations of the cross-sections showed that the as-sprayed $\mathrm{Cr}_{3} \mathrm{C}_{2}-\mathrm{NiCr}, \mathrm{NiCrBSi}$ and $\mathrm{WC}-\mathrm{CoCr}$ coatings had a thickness between 200 and $230 \mu \mathrm{m}$ (Fig. 6a, d, g). All coatings showed well-discernible lamellar microstructure with elongated splats and pores located on inter-spat boundaries. The total areal porosity of the $\mathrm{Cr}_{3} \mathrm{C}_{2}-\mathrm{NiCr}, \mathrm{NiCrBSi}$ and WCCoCr coatings estimated from SEM images was around $8.9 \%, 4.6 \%$ and 5.4 $\%$, respectively. The as-received $\mathrm{APS} \mathrm{Cr}_{3} \mathrm{C}_{2}-\mathrm{NiCr}$ coating contained isolated $\mathrm{Cr}_{3} \mathrm{C}_{2}$ carbides grains homogeneously distributed in Ni-based matrix, which 


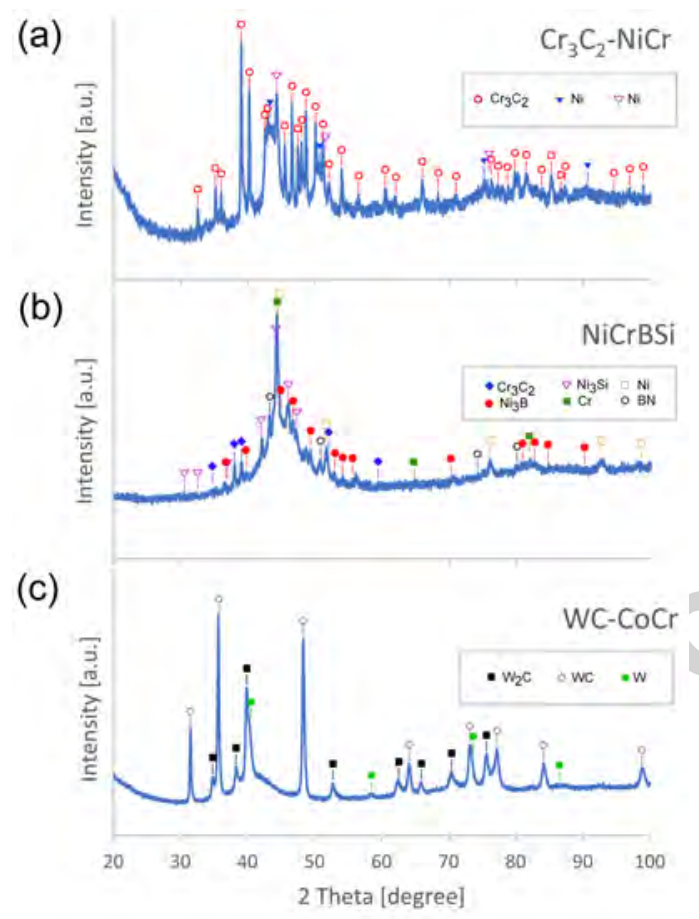

Figure 5: X-ray diffraction patterns of as-sprayed coatings (a) $\mathrm{Cr}_{3} \mathrm{C}_{2}-\mathrm{NiCr}$, (b) NiCrBSi, and (c) WC-CoCr.

showed both regions with higher (of dark grey colour) and lower (of light grey colour) Cr dissolution (Fig. 6b-c). The APS NiCrBSi coating showed the Ni-based matrix with embedded micron-sized and submicron hard phases (carbides, silicides and borides) (Fig. 6d-f). The WC-CoCr coating exhibited fine tungsten-based carbides homogeneously distributed throughout $\mathrm{CoCr}$ matrix (Fig. 6i).

The microhardness of the as-sprayed coatings increased in the following order: $\mathrm{Cr}_{3} \mathrm{C}_{2}-\mathrm{NiCr}, \mathrm{NiCrBSi}$ and WC-CoCr, being, respectively, 1.7, 2.5 and 4.0 times higher than that of the substrate steel (Fig. 7). Furthermore, studied coatings showed an order of magnitude greater variation in hardness 

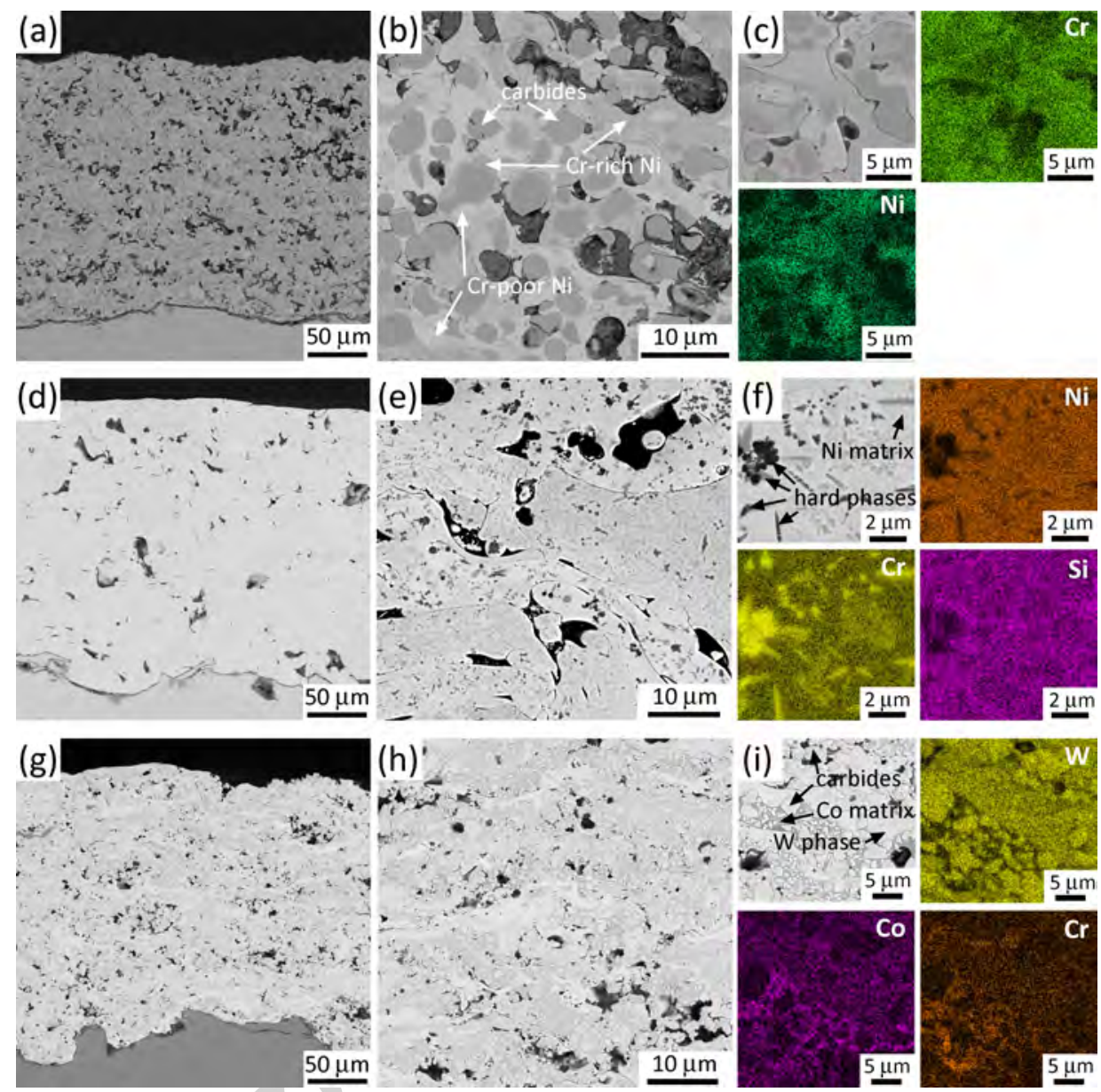

Figure 6: SEM micrographs of as-sprayed (a-c) $\mathrm{Cr}_{3} \mathrm{C}_{2}-\mathrm{NiCr}$, (d-f) $\mathrm{NiCrBSi}$, and (g-i) WC-CoCr coatings, with the EDX elemental mapping of regions shown in middle-column images.

than the reference steel, probably because of higher microstructural variation.

\subsection{Weight loss}

Wear test results revealed a significant difference between the weight loss of 2-row and 3-row rotors. For all studied materials, 2-row rotors showed noticeably greater weight loss as compared to 3-row rotors (Fig. 8a-b). De- 


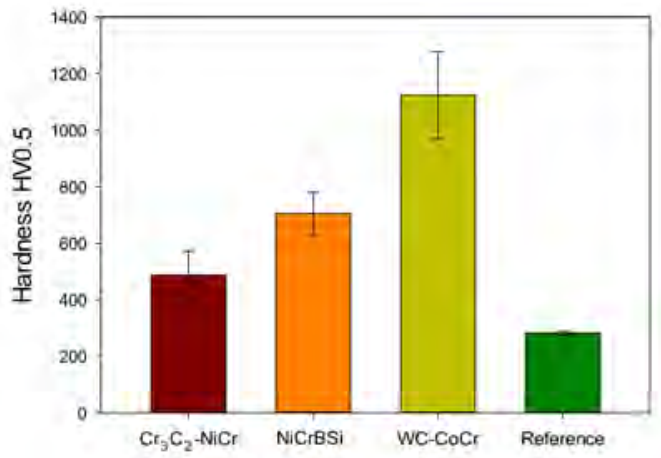

Figure 7: Vickers' hardness of studied coatings and the reference steel.

S

\section{s}

\section{co} although it was slightly less than that of the $\mathrm{NiCrBSi}$ coating in the case of 2-row rotors until reaching $10 \mathrm{~kg}$ of milled cement.

(a)

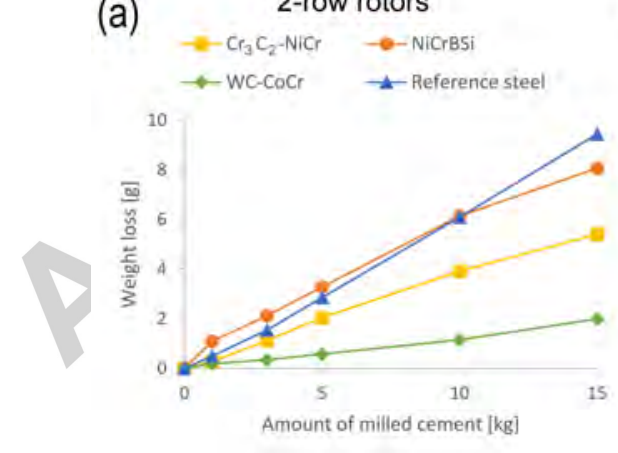

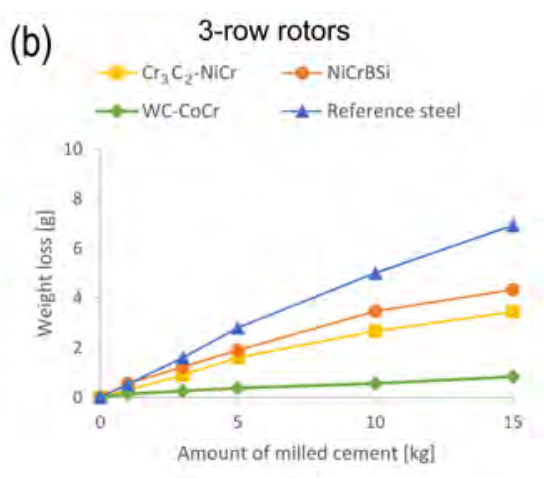

Figure 8: Weight loss of (a) 2-row rotors and (b) 3-row rotors with studied protective coatings with respect to the amount of milled Portland cement. 


\subsection{Volumetric wear of rotor pins and their morphology}

The evaluation of the volume change of grinding rotors due to erosion wear carried out with a 3D scanner revealed that the volume change occurred on the rotor pins, while the rings remained practically intact (the volume change was less than 1\%). The data of the relative volumetric loss of individual rows of pins for the different types of rotors (2-row and 3-row rotors) after milling of $15 \mathrm{~kg}$ of Portland cement are shown in Fig. 9b, where rows of pins are marked in accordance to the scheme provided in Fig. 9a. For all the materials studied, much larger relative volumetric wear was observed for 2-row rotors as compared to 3-row ones, thus corroborating the mass loss data. The overall trend in the volumetric wear of individual rows of pins is that the outer $(2 \mathrm{~A}$ and $3 \mathrm{~A}$ ) and central (3B) rows suffered more extensive wear than the inner ones (2C and $3 \mathrm{C})$.
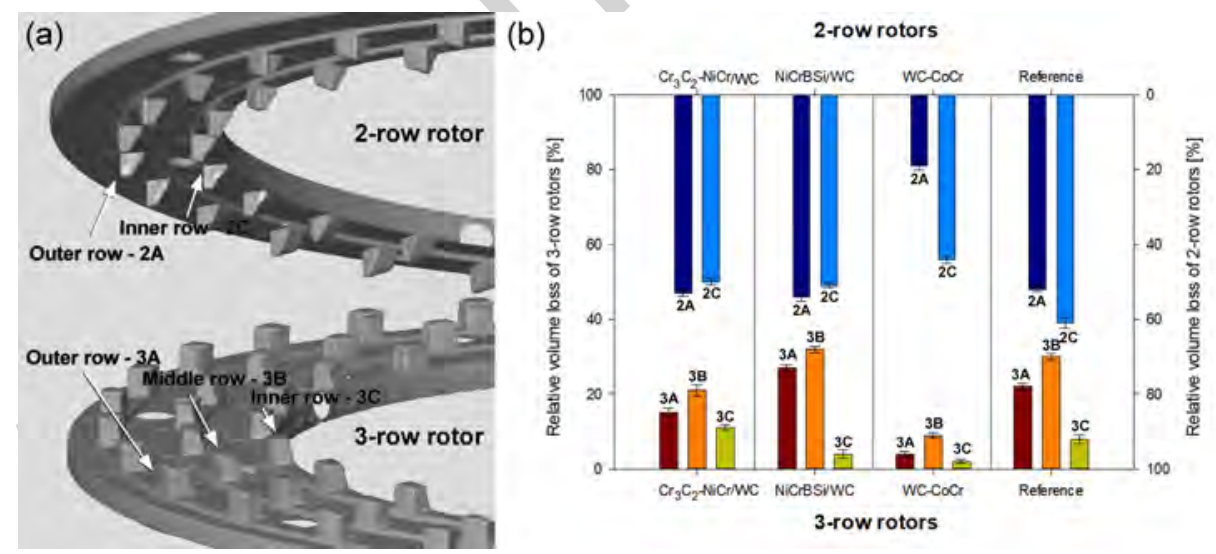

Figure 9: (a) Scheme showing the designation of rows of grinding rotor pins and (b) the relative volumetric loss after the milling of $15 \mathrm{~kg}$ of the Portland cement of the individual rows of 2-row and 3-row rotor pins.

${ }_{215}$ A 3D optical analysis of worn 2-row rotors (Fig. 10) showed that the front, 
the right lateral and the upper faces of the pins of both rows were severely worn out. Regardless of the used coating, it was completely removed from these faces, along with a substantial amount of substrate steel, resulting in a prismatic shape of pins. There was no significant difference in appearance between the two rows of pins $(2 \mathrm{~A}$ and $2 \mathrm{C})$ in the 2-row rotors. In contrast, the pins of the 3-row rotors were less damaged, though still noticeably worn, and this was distinctly different for the three rows. Pins of the outer $3 \mathrm{~A}$ row retained their initial rectangular shape to a greater extent than those from the inner $3 \mathrm{~B}$ and $3 \mathrm{C}$ rows. The faces of the pins that suffered the most intense erosive damage were the same as in the case of 2-row rotor pins, i.e. the front, the right lateral and the upper faces.

The character of the erosion damage was additionally analyzed by examining the representative cross-sections of the pins after the wear test (Fig. 11). As can be seen, in the places of the most severe erosion attack (the right lateral side of the pin), the coating was completely removed together with a significant portion of the steel substrate. Correlating these images with the mass loss of rotors, it can be concluded that a significant amount of mass loss is related to the removed substrate material rather than the coatings.

SEM examinations of the damaged surface of the pins after the erosion test revealed several distinctive morphologies shown in Figure 12. In case of the rotor with $\mathrm{Cr}_{3} \mathrm{C}_{2}-\mathrm{NiCr}$ coating, which was completely removed during the test, and the rotor from the reference steel, their surface in the site \#1 mainly exhibited both mild and deep multiple scratches, and the presence of shallow impact craters. On the other hand, NiCrBSi and WC-CoCr coatings have rather non-scratched appearance, though with some traces of spallation 


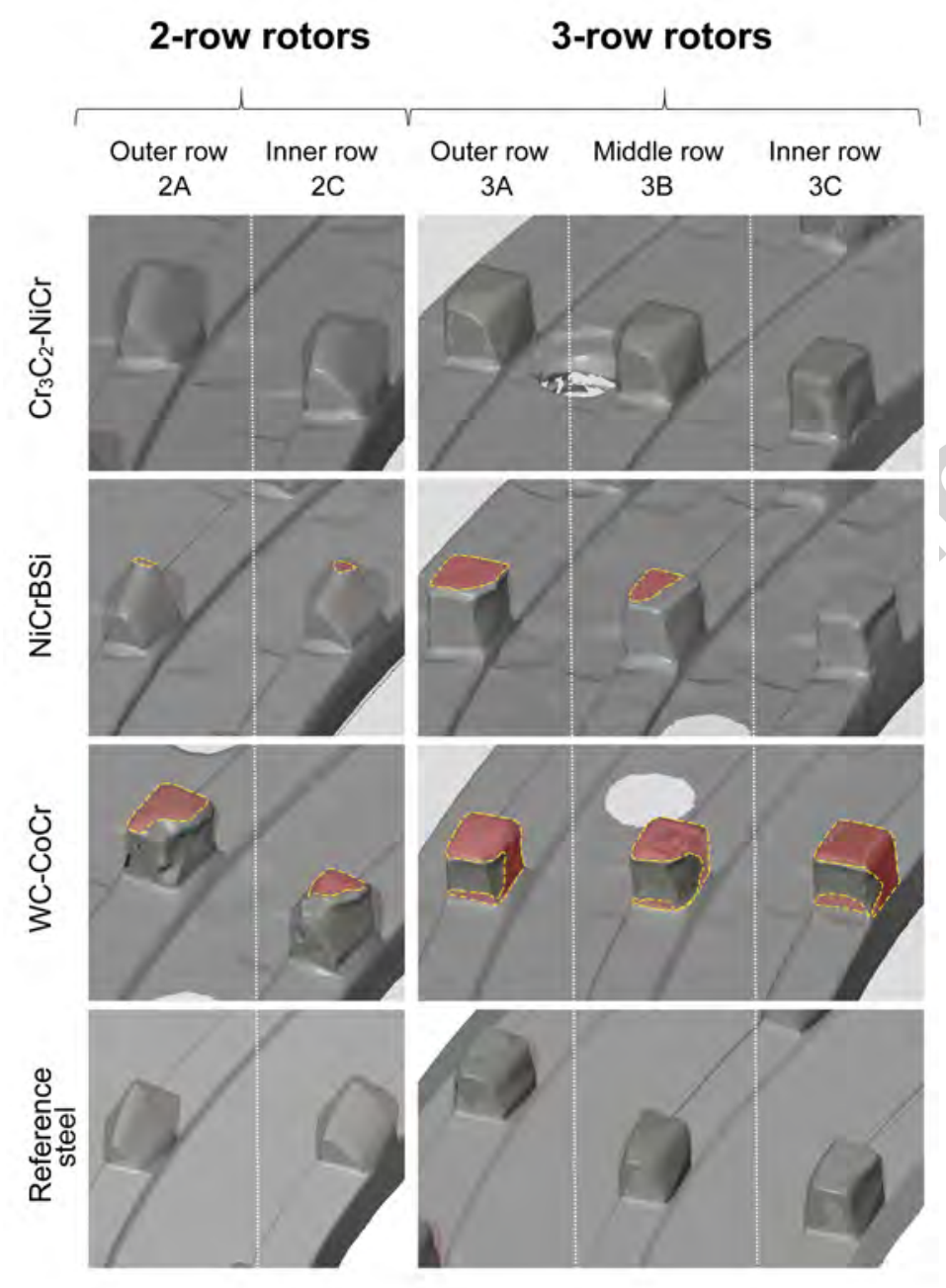

Figure 10: 3D visualization of worn rotor pins after the milling of $15 \mathrm{~kg}$ of the Portland cement as compared to their initial profiles (indicated as translucent outlines) in rotors coated with thermally-sprayed coatings and non-coated rotors. Areas with preserved coatings are indicated with dashed lines.

or microcracking. In contrast, the surface in the zone $\# 2$, in which none of the studied coatings survived the experiment, contained mostly deep impact craters and plastically deformed ridges of material extruded by impacting 


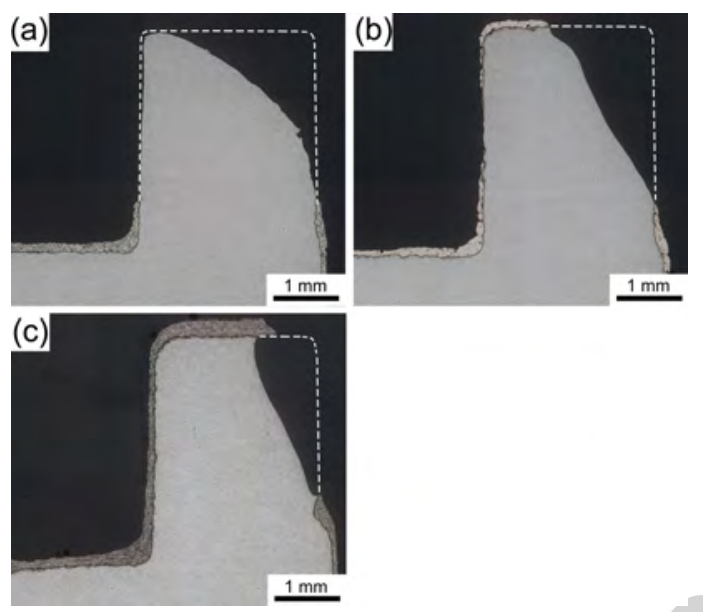

Figure 11: Micrographs of the lateral cross-sections of worn grinding rotor pins from the 2-row rotor (inner row $2 \mathrm{C}$ ) with (a) $\mathrm{Cr}_{3} \mathrm{C}_{2}-\mathrm{NiCr}$, (b) NiCrBSi and (c) WC-CoCr coatings (the profiles of non-worn pins are indicated with the dashed lines) after the milling of 15 $\mathrm{kg}$ of the Portland cement.

particles.

As shown in Fig. 10 and $12, \mathrm{Cr}_{3} \mathrm{C}_{2}-\mathrm{NiCr}$ and $\mathrm{NiCrBSi}$ coatings were completely removed in the anterior faces of the pins, however, WC-CoCr coating has been partially preserved in the anterior bottom part of the pins in 3-row rotor (Fig. 13a). SEM morphology of the eroded WC-CoCr coating surface exhibited numerous areas with characteristics of gross spalling of the coating mostly along the intersplat boundaries, material pull-out and the evidence of surface cracking (Fig. 13b).

\section{Discussion}

In this work, semi-industrial erosion tests of several thermally-sprayed coatings intended for the protection of working pins of grinding rotors of the laboratory high-speed mill were performed. The relevance of the present 
(a)
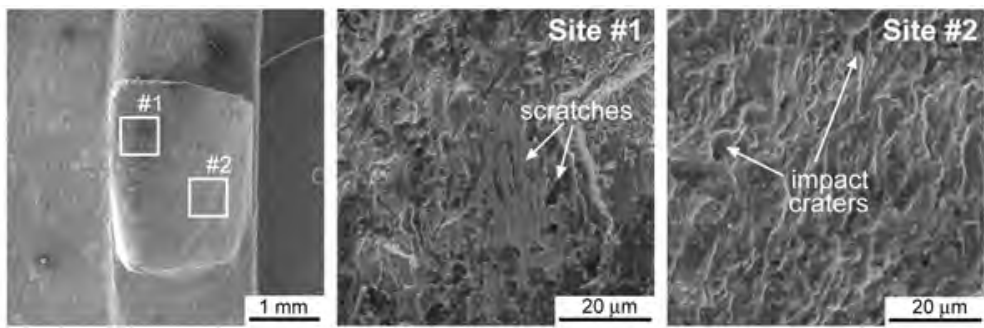

(b)
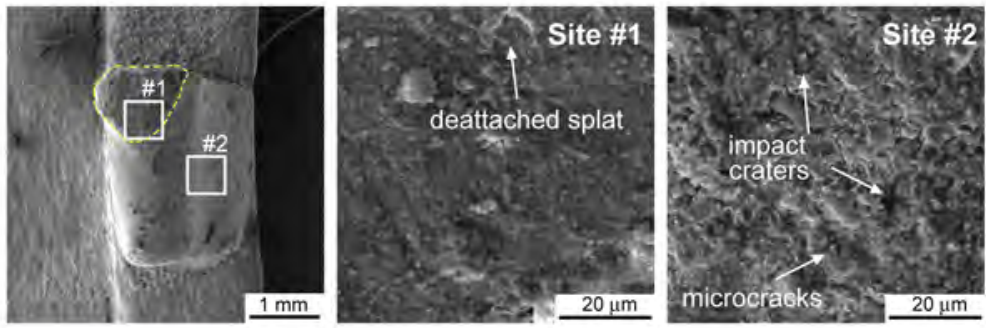

(c)
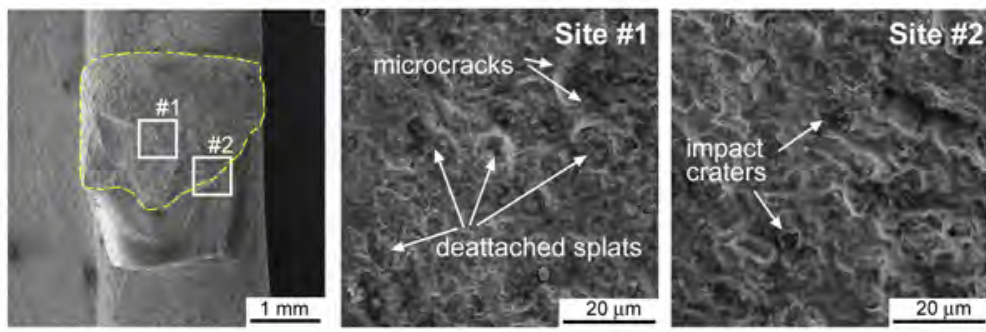

(d)

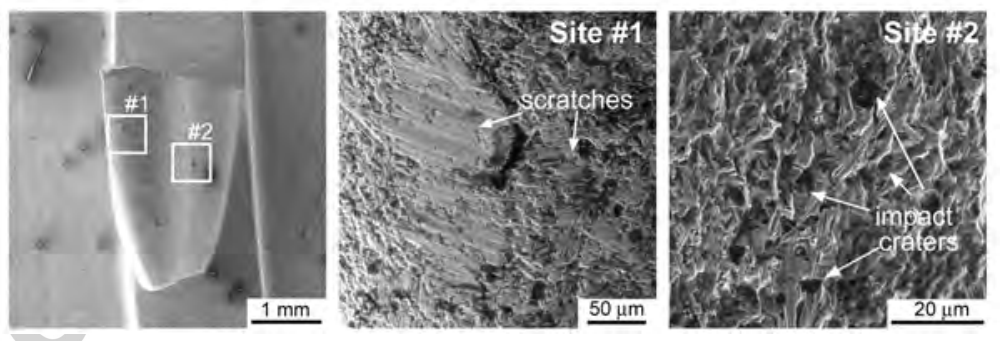

Figure 12: SEM micrographs of worn pins of 2-row rotors (inner row 2C) with (a) $\mathrm{Cr}_{3} \mathrm{C}_{2}{ }^{-}$ $\mathrm{NiCr}$, (b) NiCrBSi, (c) WC-CoCr coatings, and (d) of non-coated 2-row rotor after the milling of $15 \mathrm{~kg}$ of the Portland cement. Areas with preserved coatings are indicated with the dashed lines.

study is determined by the complexity of erosion wear processes occurring in the real operating conditions of a high-speed mill, in contrast to the model 

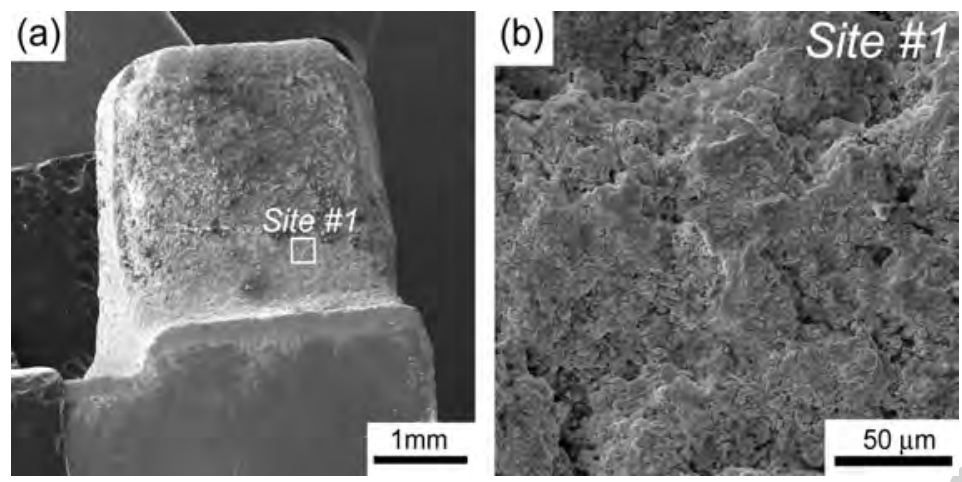

Figure 13: (a) General overview of worn pin of 3-row rotor (inner row 2C) with WC-CoCr coating after the milling of $15 \mathrm{~kg}$ of Portland cement, and (b) the appearance of preserved WC-CoCr coating from site\#1 in (a).

experiments with well-controlled testing conditions, such as those reported in $[17,18]$. The complex nature of erosion wear puts forwards special demands on protective materials, which should possess both optimal microstructure and the balanced set of mechanical properties. As it is known, various parameters of thermally-sprayed coating, such as the chosen material system, the spraying parameters, intrinsic microstructural features (reinforcement content, distribution of individual phases, bonding strength between constituents, porosity, etc.) and resulting mechanical properties (most importantly, the hardness and the fracture toughness) have strong impact on coating's performance under impact erosion conditions [30, 31]. Though, the microstructure and phase composition of the coatings produced in this study were typical representatives of their microstructural classes, and they were similar to those obtained elsewhere [24,32,33], several specific features were detected by XRD and SEM analyses. The occurrence of two Ni-based phases with the cubic lattice in the $\mathrm{Cr}_{3} \mathrm{C}_{2}-\mathrm{NiCr}$ coating was due to partial disso- 
lution of $\mathrm{Cr}$ and $\mathrm{C}$ in the $\mathrm{Ni}$ binder phase around carbide particles during APS deposition process. The WC-CoCr coating showed partial decarburisation of $\mathrm{WC}$ to $\mathrm{W}_{2} \mathrm{C}$ phase that probably occurred during the deposition process, and it has been observed in some previous studies on the HVOF WC-CoCr coatings [26]. Distinct Co peak from the binder phase was not detected in WC-CoCr coating, however, the occurrence of $\mathrm{W}$ peak indicates its possible precipitation from the melt during particle quenching following the deposition process, as reported by Stewart et al. [34].

The obtained microstructure of the thermally-sprayed coatings determines their hardness, which represent the composite hardness of hard phases and the binder phase. Apparently, a high content of submicron hard tungsten carbides in WC-CoCr coating, or Ni-based matrix reinforced with disperse carbides, borides and silicides in NiCrBSi coating provide a higher hardness than do large $\mathrm{Cr}_{3} \mathrm{C}_{2}$ carbides embedded to ductile Ni-based matrix in the case of the $\mathrm{Cr}_{3} \mathrm{C}_{2}-\mathrm{NiCr}$ coating. The previous findings on the erosive resistance of these types of coatings showed that under fixed experimental conditions (fixed impact angle and particle speed) the WC-CoCr coatings have lower abrasive/erosive wear rates due to higher hardness of WC particles, hardness and fatigue strength of the Co-based binder, and fracture toughness as compared to Ni-based $\mathrm{Cr}_{3} \mathrm{C}_{2}-\mathrm{NiCr}$ and $\mathrm{NiCrSiB}$ coatings $[18,26]$. In general, high hardness is advantageous for the conditions of erosion wear at low impact angles, where material is removed from the surface by the mechanisms of plastic deformation by abrasive particles and microcutting (provided that the hardness of abrasive material, $H_{A}$, is larger than that of the abraded target, $H_{T} ; H_{A} / H_{T}>1.2$ [35]). However, for the conditions of 
mixed erosion, when damage involves the brittle fracture and surface fatigue wear mechanisms, the wear resistance of a coating is more dependent on size, shape, and distribution of hard phases than on their hardness [36]. The weight loss data corroborated this, showing no direct correlation between the hardness of studied coatings and their weight loss. Rotors coated with WC-CoCr and $\mathrm{Cr}_{3} \mathrm{C}_{2}$-NiCr protective coatings, which have lower and higher hardness than that of the NiCrBSi coating, showed lower weight loss. In this case, the resulting wear resistance is determined by the set of various characteristics (hardness, fracture toughness, porosity, adhesion between coating microstructural features, etc.) rather than by the hardness alone. Also, it should be kept in mind that the weight loss here is a cumulative characteristic, which comprises the wear loss from both the coating and the substrate. Due to the relatively small thickness of the coatings $(\sim 200-230 \mu \mathrm{m})$, the weight loss of the pins is mainly contributed by the wear of steel substrate, as shown by the microstructural analysis presented in Fig. 11 and 12 . In this context, the coating can be considered more erosion-resistant if it better protects the substrate against material removal and volume change by erosion, which is the main reason for the reduction of the grinding efficiency [9]. For this reason, NiCrBSi coating can be considered less erosion-resistant than $\mathrm{Cr}_{3} \mathrm{C}_{2}-\mathrm{NiCr}$, even though it has been better preserved top of the pins. Such a wear behavior is determined by the different wear mechanisms acting in different pin faces.

The predominant wear mechanisms operating on various surfaces of rotor pins (Figure 14) were determined using 3D optical scanner, light microscope, and SEM examinations. Regardless of the protective coating used, the an- 
terior and the right lateral faces of pins (area I in Fig. 14) experienced almost complete failure of the coating that was followed by loss of a great amount of steel substrate (Fig. 11-13). These faces were obviously subjected to the impingement with cement particles traveling at rather high angles, as evidenced by the appearance of numerous impact craters with plastically deformed flakes at their corners. Under such conditions, the material removal from the eroded surface can occur by either one or by a combination of (i) brittle fracture of carbide particles and the development of inter-splat cracks that lead to extensive spalling of the coating, or (ii) repeated surface deformation of ductile binder phase or steel substrate and following generation of surface and subsurface cracks, which is accompanied by carbide particle pull-outs, making the surface fatigue a dominating wear mechanism $[14,37]$. Combination of these wear mechanisms are typically observed in thermally-sprayed coatings eroded at high impact angles [38]. SEM analysis of the partially preserved WC-CoCr coating in the bottom anterior part of the 3-row pins (Fig. 13) made it possible to establish wear mechanism, which mainly included plastic deformation of binder phase with impinging cement particles followed with material detachment and crack generation in the intercarbide areas. The intersplat boundaries, interface between the binder and carbides, and porosity represent potential sites for crack nucleation due to higher stress concentration [18]. As for $\mathrm{Cr}_{3} \mathrm{C}_{2}-\mathrm{NiCr}$ and $\mathrm{NiCrBSi}$ coatings, since they were completely removed from these faces of pins, it was impossible to establish directly the operating wear mechanisms. Nevertheless, given the microstructural condition of all coatings (i.e., disperse carbide grains in the ductile binder phase), it can be concluded that the erosion of these ma- 
terials at high impact angles occurs in a similar manner, as ealier observed in model experiments $[18,26,37,38]$. Due to the relatively low hardness of the cement particles compared with carbides and relatively small carbide size, direct fracture or microchipping of carbide phases seems unlikely.

In contrast, the impacts on the top and left-side faces of pins (zone II in Fig. 14) occurs mostly at low impact angles, as confirmed by abrasive scratches and grooves (Fig. 12). Material in these areas is removed due to ploughing and cutting by cement particles travelling along the tangent trajectories, and the dominating wear mechanism here is abrasion. In accordance with Hutchings [35], the wear degree of pin faces subjected to oblique impact could be explained by the ratio between the hardness of Portland cement particles and the hardness of the coating, i.e. the higher the hardness of the coating over that of the milled cement, the less intense is abrasive wear. Hence, the $\mathrm{Cr}_{3} \mathrm{C}_{2}-25 \mathrm{NiCr}$ coating, which has lower hardness than of the cement particles $(\sim 600-650 \mathrm{HV})$, was totally worn out in the zone II due to abrasion. At the same time, the NiCrBSi and WC-CoCr coatings with higher hardness were partially preserved, hence, representing an evident advantage over the $\mathrm{Cr}_{3} \mathrm{C}_{2}-25 \mathrm{NiCr}$ coating (and other more ductile coatings) and the steel substrate.

An additional important information on the character of erosion processes occurring in the milling system was provided by the evaluation of uniformity of wear of grinding rotors by means of 3D optical scanner. Obtained data provide a possibility to properly adjust the coating deposition parameters in order to achieve longer lifetime of the grinding system. The disproportion of the amount of material removed by erosion between 2-row rotors and 3-row 


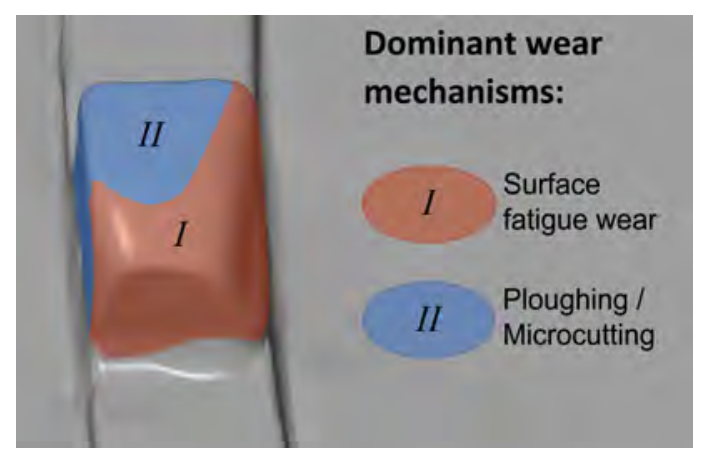

Figure 14: Operating wear mechanisms on different surfaces of a typical grinding rotor's pin.

rotors, as well as occurrence of the most intensive erosive damage in $2 \mathrm{~A}$, $2 \mathrm{C}$, and $3 \mathrm{~B}$ rows can be primarily explained by the design of the mill and resulting variability of milling process parameters at different sites of the milling system. According to previous studies on erosion by liquid/gas-borne particle streams [39-41], the most important parameters relevant to our case are the cement particle size, particle flux (i.e., the number of impinging particles per unit area), particle velocity, and the impact angle. According to the scheme in Fig. 2c, the material to be milled enters the milling chamber through the inlet in the center of the 2-row rotor and makes the first contact with the first row of pins on the 3-row rotor. Apparently, this first contact at this row of pins occurs at relatively low speeds and at high impact angles and, therefore, erosion damage occurs mostly at the anterior faces of the pins (inner row 3C in Fig. 10) and the resulting volumetric loss is relatively small. After that, these pins propel the cement particles to the first row of pins of the 2-row rotor (inner row $2 \mathrm{C}$ in Fig. 10), where the impact is carried out by still quite large particles traveling at much higher velocities 
and at different angles (both low and high). The same situation is repeated between the second row of the 3-row rotor and the second row of the 2-row rotor (middle row 3B and outer row 2A in Fig. 10, respectively). Since it is generally accepted that higher impact velocity increase the erosion rate $[39,41]$, abrasive particles located between the 2A, 2C, and 3B rows, which are still relatively large massive and have high impact velocities, have enough kinetic energy at impact to produce high erosive damage of pins. Hence, extensive erosion wear occurs not only on the anterior, but also at the side surfaces of the rotor pins.

Further decrease in volumetric wear of the third row of pins (outer row 3A in Fig. 10) may be caused by two main reasons, including (i) the mass reduction of initial rough particles, and (ii) increase in particle flux, both due to fragmentation of the initial coarse particles. The mass reduction of particles due to their fragmentation during previous milling stages apparently results in the decrease of their kinetic energy at impact. This is in accordance with generally accepted consideration that smaller particles cause lower mass loss by erosion than the same mass of larger particles [39]. As for the particleparticle interactions, it has been shown that higher particle flux may reduce the erosion rate by increasing the collision frequency of particles released into the milling system. Incident particles collide with rebounding particles, diverting a portion of incident particles away from the target surface and reducing kinetic energy $[39,41]$. In our case, the fragmentation of initial cement particles leads to the production of high number of smaller particles, thus increasing the particle flux and probability of interactions between the incident and rebounding particles. 
414

\section{Conclusions}

In the present work, the erosion resistance of several types of protective coatings under semi-industrial conditions was evaluated using a laboratory high-speed mill. The most wear resistant was the HVOF-sprayed WC-CoCr coating, followed by the APS-sprayed $\mathrm{Cr}_{3} \mathrm{C}_{2}-25 \mathrm{NiCr}$ and $\mathrm{NiCrBSi}$ coatings. WC-CoCr has both the lowest weight loss and minimal topographical changes of the working pins on the grinding rotors after erosion test. Responsible wear mechanisms have been established that act on different faces of the rotor pins. The surface fatigue wear caused the greatest loss of material and complete failure of all protective coatings on the anterior and the right lateral faces of the pins. Ploughing and microcutting were acting on the top and left lateral faces of the pins and resulted in noticeable damage of the protective coatings when their hardness was lower than that of incident cement particles. Furthermore, this study also revealed a significant disproportion of wear between various rows of grinding rotors. The central rows of pins of the milling system comprising two counter rotors (both rows of 2-row rotor and the middle row of 3-row rotor) suffered more intensive erosion wear than the external ones (outer rows of 3-row rotor). The design of the mill and the resulting variability in milled powder parameters (such as particle size, particle flux and particle velocity) at different sites of the milling system were considered as main reasons for this effect. These conclusions indicate a further need to optimize the coating deposition process to better tailor its microstructural parameters in order to protect the most critical parts of the milling system (and perhaps, to further optimize the design of working parts the mill). 


\section{Acknowledgement}

This study was carried out with the financial support from the Ministry of Education, Youth and Sports of Czech Republic under the projects CEITEC 2020 (LQ1601; under National Sustainability Program II) and AdMaS UP (LO1408; under National Sustainability Programme I), and from the Czech Science Foundation under the project "Study of the effects of samples preparation on the final properties of inorganic binders" (15-08755S). The authors acknowledge Dr. Zdenĕk Spotz for technical assistance during sample characterization. Part of the work was carried out with the support of core facilities of research infrastructure CEITEC Nano of CEITEC-BUT (MEYS CR, 2016-2019).

\section{References}

[1] A. Tymanok, P. Kulu, Treatment of different materials by disintegrator systems, Proceedings of the Estonian Acad. Sci. Eng. 5 (3) (1999) 222242 .

[2] V. V. Boldyrev, Mechanochemistry and mechanical activation of solids, Solid State Ionics 63-65 (Supplement C) (1993) 537-543. doi:https://doi.org/10.1016/0167-2738(93)90157-X.

[3] K. Dvořák, I. Hajková, The effect of high-speed grinding technology on the properties of fly ash, Materiali in tehnologije 50 (5) (2016) 683-687. doi:10.17222/mit.2015.127.

[4] P. Baláž, Mechanochemistry in Nanoscience and Minerals Engineering, 
Springer Berlin Heidelberg, Berlin, Heidelberg, 2008. doi:10.1007/9783-540-74855-7.

[5] R. Hamzaoui, O. Bouchenafa, S. Guessasma, N. Leklou, A. Bouaziz, The sequel of modified fly ashes using high energy ball milling on mechanical performance of substituted past cement, Materials \& Design 90 (Supplement C) (2016) 29-37. doi:https://doi.org/10.1016/j.matdes.2015.10.109.

[6] J. C. Arteaga-Arcos, O. A. Chimal-Valencia, H. T. Yee-Madeira, S. Díaz de la Torre, The usage of ultra-fine cement as an admixture to increase the compressive strength of Portland cement mortars, Construction and Building Materials 42 (2013) 152-160. doi:https://doi.org/10.1016/j.conbuildmat.2013.01.017.

[7] S. Kumar, A. Bandopadhyay, V. Rajinikanth, T. C. Alex, R. Kumar, Improved processing of blended slag cement through mechanical activation, Journal of Materials Science 39 (10) (2004) 3449-3452. doi:10.1023/B:JMSC.0000026948.85440.cc.

URL https://doi.org/10.1023/B: JMSC.0000026948.85440.cc

[8] S. Kumar, P. García-Triñanes, A. Teixeira-Pinto, M. Bao, Development of alkali activated cement from mechanically activated silico-manganese (SiMn) slag, Cement and Concrete Composites 40 (2013) 7-13. doi:https://doi.org/10.1016/j.cemconcomp.2013.03.026. URL http://www.sciencedirect.com/science/article/pii/ S0958946513000450 
483

[9] K. Dvořák, D. Dolák, D. Paloušek, L. Ćelko, D. Jech, The Effect of the Wear of Rotor Pins on Grinding Efficiency in a High-speed Disintegrator, Materials Science Medžiagotyra 24. doi:http://dx.doi.org/10.5755/j01.ms.24.1.17737.

[10] P. Niranatlumpong, H. Koiprasert, Phase transformation of NiCrBSi WC and NiBSiWC arc sprayed coatings, Surface and Coatings Technology $206 \quad$ (2) (2011) 440-445. doi:https://doi.org/10.1016/j.surfcoat.2011.07.057.

[11] K. Szymański, A. Hernas, G. Moskal, H. Myalska, Thermally sprayed coatings resistant to erosion and corrosion for power plant boilers - A review, Surface and Coatings Technology 268 (Supplement C) (2015) 153-164. doi:https://doi.org/10.1016/j.surfcoat.2014.10.046.

[12] M. Oksa, T. Varis, K. Ruusuvuori, Performance testing of iron based thermally sprayed HVOF coatings in a biomass-fired fluidised bed boiler, Surface and Coatings Technology 251 (Supplement C) (2014) 191-200. doi:https://doi.org/10.1016/j.surfcoat.2014.04.025.

[13] R. B. Heimann, Plasma Spray Coating, Wiley, 2008.

[14] P. Kulu, I. Hussainova, R. Veinthal, Solid particle erosion of thermal sprayed coatings, Wear 258 (1-4) (2005) 488-496. doi:10.1016/J.WEAR.2004.03.021.

[15] L. Thakur, N. Arora, R. Jayaganthan, R. Sood, An investigation on erosion behavior of $\mathrm{HVOF}$ sprayed $\mathrm{WC}-\mathrm{CoCr}$ 
coatings, Applied Surface Science 258 (3) (2011) 1225-1234. doi:https://doi.org/10.1016/j.apsusc.2011.09.079.

[16] A. Kumar, A. Sharma, S. K. Goel, Erosion behaviour of WC $10 \mathrm{Co} 4 \mathrm{Cr}$ coating on $23-8-\mathrm{N}$ nitronic steel by HVOF thermal spraying, Applied Surface Science 7 (Supplement C) (1998) 418-426. doi:https://doi.org/10.1016/j.apsusc.2016.02.163.

[17] L. Thakur, N. Arora, A comparative study on slurry and dry erosion behaviour of HVOF sprayed WC CoCr coatings, Wear 303 (1) (2013) 405-411. doi:https://doi.org/10.1016/j.wear.2013.03.028.

[18] N. Vashishtha, R. K. Khatirkar, S. G. Sapate, Tribological behaviour of HVOF sprayed WC-12Co, WC-10Co-4Cr and $\mathrm{Cr} 3 \mathrm{C} 2-25 \mathrm{NiCr}$ coatings, Tribology International 105 (Supplement C) (2017) 55-68. doi:https://doi.org/10.1016/j.triboint.2016.09.025.

[19] D. Goljandin, P. Kulu, Disintegrators and Disintegrator Treatment of Materials, LAP LAMBERT Academic Publishing, 2015.

[20] Vardelle, P. Fauchais, Thermal Sprayed Coatings Used Against Corrosion and Corrosive Wear, in: H. Salimi Jazi (Ed.), Advanced Plasma Spray Applications, InTech, Rijeka, 2012, Ch. 1. doi:10.5772/34448.

URL https://doi.org/10.5772/34448

[21] W. Zhou, K. Zhou, Y. Li, C. Deng, K. Zeng, High temperature wear performance of HVOF-sprayed $\mathrm{Cr} 3 \mathrm{C} 2-\mathrm{WC}-\mathrm{NiCoCrMo}$ and $\mathrm{Cr} 3 \mathrm{C} 2-$ NiCr hardmetal coatings, Applied Surface Science 416 (2017) 33-44. doi:https://doi.org/10.1016/j.apsusc.2017.04.132. 
URL http://www.sciencedirect.com/science/article/pii/ S0169433217311595

[22] K. Murugan, A. Ragupathy, V. Balasubramanian, K. Sridhar, Optimizing HVOF spray process parameters to attain minimum porosity and maximum hardness in $\mathrm{WC}$ ?10Co?4Cr coatings, Surface and Coatings Technology 247 (2014) 90-102. doi:https://doi.org/10.1016/j.surfcoat.2014.03.022.

URL http://www.sciencedirect.com/science/article/pii/ S0257897214002394

[23] R. J. K. Wood, Tribology of thermal sprayed WC?Co coatings, International Journal of Refractory Metals and Hard Materials 28 (1) (2010) 82-94. doi:https://doi.org/10.1016/j.ijrmhm.2009.07.011.

URL http://www.sciencedirect.com/science/article/pii/ S0263436809001012

[24] S. Matthews, B. James, M. Hyland, The role of microstructure in the high temperature oxidation mechanism of $\mathrm{Cr}_{3} \mathrm{C}_{2} \mathrm{NiCr}$ composite coatings, Corrosion Science 51 (5) (2009) 1172-1180. doi:https://doi.org/10.1016/j.corsci.2009.02.027.

[25] Z. Q. Zhang, H. D. Wang, B. S. Xu, G. S. Zhang, Characterization of microstructure and rolling contact fatigue performance of NiCrBSi/WC Ni composite coatings prepared by plasma spraying, Surface and Coatings Technology 261 (Supplement C) (2015) 60-68. doi:https://doi.org/10.1016/j.surfcoat.2014.11.061. 
[26] J. K. N. Murthy, D. S. Rao, B. Venkataraman, Effect of grinding on the erosion behaviour of a WC Co Cr coating deposited by HVOF and detonation gun spray processes, Wear 249 (7) (2001) 592-600. doi:https://doi.org/10.1016/S0043-1648(01)00682-2.

[27] R. Mejdoub, H. Hammi, M. Khitouni, J. J. Suñol, A. M'nif, The effect of prolonged mechanical activation duration on the reactivity of Portland cement: Effect of particle size and crystallinity changes, Construction and Building Materials 152 (2017) 1041-1050. doi:https://doi.org/10.1016/j.conbuildmat.2017.07.008.

[28] J. J. Assaad, S. E. Asseily, J. Harb, Effect of specific energy consumption on fineness of portland cement incorporating amine or glycolbased grinding aids, Materials and Structures 42 (8) (2009) 1077-1087. doi:10.1617/s11527-008-9444-0.

[29] W. Kurdowski, Cement and concrete chemistry, Vol. 9789400779, 2014. arXiv:arXiv:1011.1669v3, doi:10.1007/978-94-007-7945-7.

[30] I. Hussainova, J. Kubarsepp, J. Pirso, Mechanical properties and features of erosion of cermets, Wear 250 (1) (2001) 818-825. doi:https://doi.org/10.1016/S0043-1648(01)00737-2.

[31] P. Kulu, Selection of Powder Coatings for Extreme Erosion Wear Conditions, Advanced Engineering Materials 4 (6) (2002) 392-397. doi:10.1002/1527-2648(20020605)4:6<392::AID-ADEM392>3.0.CO;2F. 
573

[32] J. A. Picas, M. Punset, M. T. Baile, E. Martín, A. Forn, Properties of WC-CoCr Based Coatings Deposited by Different HVOF Thermal Spray Processes, Plasma Processes and Polymers 6 (S1) (2009) S948S953. doi:10.1002/ppap.200932402.

[33] J. Barber, B. G. Mellor, R. J. K. Wood, The development of subsurface damage during high energy solid particle erosion of a thermally sprayed WC Co Cr coating, Wear 259 (1) (2005) 125-134. doi:https://doi.org/10.1016/j.wear.2005.02.008.

[34] D. A. Stewart, P. H. Shipway, D. G. McCartney, Microstructural evolution in thermally sprayed WC Co coatings: comparison between nanocomposite and conventional starting powders, Acta Materialia 48 (7) (2000) 1593-1604. doi:https://doi.org/10.1016/S13596454(99)00440-1.

[35] I. M. Hutchings, Tribology: Friction and Wear of Engineering Materials, Friction and Wear of Engineering Materials, Edward Arnold, 1992.

[36] H. Winkelmann, M. Varga, E. Badisch, H. Danninger, Wear Mechanisms at High Temperatures: Part 2: Temperature Effect on Wear Mechanisms in the Erosion Test, Tribology Letters 34 (3) (2009) 167-175. doi:10.1007/s11249-009-9425-7.

[37] I. Hussainova, J. Kübarsepp, I. Shcheglov, Investigation of impact of solid particles against hardmetal and cermet targets, Tribology International 32 (6) (1999) 337-344. doi:https://doi.org/10.1016/S0301679X(99)00073-0. 
URL http://www.sciencedirect.com/science/article/pii/ S0301679X99000730

[38] M. R. Ramesh, S. Prakash, S. K. Nath, P. K. Sapra, B. Venkataraman, Solid particle erosion of HVOF sprayed WC-Co/NiCrFeSiB coatings, Wear 269 (3) (2010) 197-205. doi:https://doi.org/10.1016/j.wear.2010.03.019.

[39] H. Uuemõis, H. Kangur, I. Veerus, Wear in high-speed impact mills, International Journal of Mineral Processing 44-45 (Supplement C) (1996) 301-313. doi:https://doi.org/10.1016/0301-7516(95)00041-0.

[40] R. S. Lynn, K. K. Wong, H. M. Clark, On the particle size effect in slurry erosion, Wear 149 (1) (1991) 55-71. doi:https://doi.org/10.1016/00431648(91)90364-Z.

[41] V. B. Nguyen, Q. B. Nguyen, C. Y. H. Lim, Y. W. Zhang, B. C. Khoo, Effect of air-borne particle particle interaction on materials erosion, Wear 322-323 (Supplement C) (2015) 17-31. doi:https://doi.org/10.1016/j.wear.2014.10.014. 